\title{
Procedural and Conceptual Knowledge: Exploring the Gap Between Knowledge Type and Knowledge Quality
}

\section{Citation}

Star, Jon R., and Gabriel J. Stylianides. 2013. Procedural and Conceptual Knowledge: Exploring the Gap Between Knowledge Type and Knowledge Quality. Canadian Journal of Science, Mathematics, and Technology Education 13, no. 2:169-181.

\section{Published Version}

doi:10.1080/14926156.2013.784828

\section{Permanent link}

http://nrs.harvard.edu/urn-3:HUL.InstRepos:10752457

\section{Terms of Use}

This article was downloaded from Harvard University's DASH repository, and is made available under the terms and conditions applicable to Open Access Policy Articles, as set forth at http:// nrs.harvard.edu/urn-3:HUL.InstRepos:dash.current.terms-of-use\#OAP

\section{Share Your Story}

The Harvard community has made this article openly available.

Please share how this access benefits you. Submit a story.

\section{Accessibility}


Running head: PROCEDURAL AND CONCEPTUAL KNOWLEDGE

Procedural and Conceptual Knowledge: Exploring the Gap Between Knowledge Type and Knowledge Quality

Jon R. Star

Harvard University

Gabriel J. Stylianides

University of Oxford

December 23, 2012

To appear in the Canadian Journal of Science, Mathematics, and Technology Education DOI:10.1080/14926156.2013.784828

Estimated publication date: May 2013 (online), June 2013 (print) 


\begin{abstract}
Following Star $(2005,2007)$ we continue to problematize the entangling of type and quality in the use of conceptual knowledge and procedural knowledge. Although those whose work is guided by types of knowledge and those whose work is guided by qualities of knowledge seem to be referring to the same phenomena, actually they are not. This lack of mutual understanding of both the nature of the questions being asked and the results being generated causes difficulties for the continued exploration of questions of interest in mathematics teaching and learning, such as issues of teachers’ knowledge.
\end{abstract}

Keywords: Conceptual knowledge, mathematics, procedural knowledge, student learning, teacher knowledge 
Procedural and Conceptual Knowledge: Exploring the Gap Between Knowledge Type and Knowledge Quality

Over the past century, many different terminological frameworks have been used in the mathematics teaching and learning literature to describe knowledge outcomes of interest, including meaning theory (Brownell, 1944/1945), relational/instrumental understanding (Skemp, 1976), and routine and adaptive expertise (Hatano \& Inagaki, 1986). However, since the mid-1980s, the most prevalent of these frameworks is one comprised of two major kinds of knowledge, conceptual knowledge and procedural knowledge. Although the origins of this framework are hard to identify precisely, it became widely known after the publication of a book edited by Hiebert (1986).

There are at least three reasons why it is useful or even essential for those interested in mathematics teaching and learning to have a terminological framework for particular aspects of students' or teachers' mathematical knowledge. First, these frameworks can ostensibly allow for the articulation of our goals for students' learning of mathematics. Second, these frameworks can allow for discussion of mechanisms for how we think these learning goals can be attained, and particularly how teaching or curriculum should appear in order to promote the learning goals. Finally, these frameworks can allow for discussion of how researchers can investigate and assess whether students are achieving desired learning goals.

The power of a terminological framework is in its potential ability to encapsulate a rich and nuanced collection of ideas about teaching and learning into a few phrases. However, for this power to be realized, at least two conditions must be satisfied.

The first condition is for the terminological framework to be able to describe a broad range of knowledge outcomes that are important to those interested in mathematics teaching and learning, in addition to providing mechanisms for achieving and assessing these 
outcomes. A framework that describes only a subset of knowledge outcomes may not be optimal because it does not allow for the full complexity of knowledge to be captured or for connections among different kinds of knowledge to be made. For example, Star $(2005,2007)$ identified two kinds of knowledge, “deep procedural knowledge” and “superficial conceptual knowledge", that, he argued, were not easy to describe with the conceptual/procedural framework, thus raising questions about the utility of the framework.

The second condition is that there must be general agreement among users of the terminological framework about the set of rich and nuanced ideas that it encapsulates. For those interested in mathematics teaching and learning, it is important to know that what one user means by "conceptual knowledge” is generally the same as what other users mean by this phrase. In the absence of such agreement, policy statements will be difficult to interpret: Teachers may agree that instruction should focus on conceptual knowledge, but this policy recommendation will be difficult to implement if teachers do not have a common understanding on what conceptual knowledge is. Similarly, such agreement is also critical for researchers. If a study finds that an intervention leads to gains in conceptual knowledge, for example, this result is difficult to interpret unless we know how the researcher defined, operationalized, and assessed conceptual knowledge.

In this paper, our focus is on the influential conceptual/procedural framework and on the second condition described above, which relates to the importance of general agreement among users about the meaning of the terms included in this terminological framework. Building on a distinction highlighted by Star (2005) between types and qualities of knowledge, we aim to show that, within the community of scholars who are interested in mathematics teaching and learning, many tend to conceive of conceptual and procedural knowledge as types of knowledge (especially in the psychological research community), while many others think of this framework in terms of qualities of knowledge (especially in 
the mathematics education research community). As a result of these different interpretations of the conceptual/procedural framework, there is a lack of mutual understanding of both the nature of the questions being asked and the results being generated. This causes difficulties for the continued exploration of issues of interest in mathematics teaching and learning, including issues such as teachers' knowledge. For example, as we illustrate in a following section, a teacher's approach to students' mathematical work draws in complex ways on personal "conceptual knowledge” and "procedural knowledge” and for this to be captured (discussed, studied, described, etc.) appropriately, there needs to be a clear and nuanced description of both qualities and types of teachers' knowledge.

\section{Conceptual and Procedural Knowledge Framework}

The conceptual and procedural knowledge framework derives essentially from the ways one conceptualizes the terms "conceptual knowledge” and "procedural knowledge”. When asked to provide definitions of conceptual and procedural knowledge, many scholars cite the opening chapter of Hiebert's 1986 edited book. Conceptual knowledge is typically defined as:

... knowledge that is rich in relationships. It can be thought of as a connected web of knowledge, a network in which the linking relationships are as prominent as the discrete pieces of information. Relationships pervade the individual facts and propositions so that all pieces of information are linked to some network. (Hiebert \& Lefevre, 1986, pp. 3-4).

Procedural knowledge is defined in terms of two kinds of knowledge:

One kind of procedural knowledge is a familiarity with the individual symbols of the system and with the syntactic conventions for acceptable configurations of symbols. The second kind of procedural knowledge consists of rules or procedures for solving 
mathematical problems. Many of the procedures that students possess probably are chains of prescriptions for manipulating symbols (Hiebert \& Lefevre, 1986, pp. 7-8).

Drawing on work by De Jong and Ferguson-Hessler (1996), Star (2005) critiqued the conceptual/procedural framework by invoking the distinction between knowledge type and knowledge quality. Knowledge quality refers to the way that something is knownessentially how well it is understood. Knowledge can be known at a deep level, at a superficial level, and anything in between the two extremes. Deep-level knowledge is linked with understanding, flexibility, evaluation, and critical judgment (De Jong \& FergusonHessler, 1996), while superficial or surface-level knowledge is linked with rote learning, reproduction, and inflexibility (Glaser, 1991). In contrast, knowledge type merely refers to what is known. With this distinction, the adjectives "conceptual” and "procedural” demarcate what type of knowledge is being characterized. Thus conceptual knowledge would refer to knowledge of concepts, including principles and definitions; procedural knowledge would refer to knowledge of procedures, including action sequences and algorithms used in problem solving.

Star $(2005,2007)$ argued that frequent usage of the terms conceptual and procedural knowledge in the mathematics education research community entangles knowledge type and quality, in which the common view of conceptual knowledge is knowledge that is known deeply, while procedural knowledge is knowledge that is known superficially (see Table 1). We will not revisit this argument here. Rather, in the interest of illustrating that different communities of scholars tend to use the conceptual/procedural framework in distinct ways, we will present one set of studies (from psychological research) where conceptual and procedural knowledge are defined primarily as types, in contrast to another set of studies (from mathematics education research) where conceptual and procedural knowledge are defined primarily as qualities. Before doing so, however, we situate our discussion of 
conceptual and procedural knowledge within the mathematical work that is core to the teaching of mathematics.

Assessing Procedural and Conceptual Knowledge in a Mathematical Task

In this section, we use a mathematical task (the Fractions Task; see Figure 1), in order to introduce a key question we discuss in this paper: "What can be considered as procedural/conceptual knowledge?”, paying particular attention to the characteristics of mathematical knowledge teachers need in their approach to students' mathematical work. The Fractions Task was part of a pre- and post-measure of knowledge about reasoning-andproving that Stylianides and Stylianides developed in their 4-year design experiment in a mathematics course for prospective elementary teachers in the United States (e.g., Stylianides \& Stylianides, 2009, 2010). Given our purposes in this article, this task affords us an opportunity to explore the constructs of procedural and conceptual knowledge in the context of an instructional situation where mathematical and pedagogical considerations come into play. In particular, we consider whether (and if so how) parts B and C of the Fraction Task assess prospective teachers' procedural knowledge and/or conceptual knowledge. [Note that the pedagogical situation in this task is similar to the one discussed by Rowland and Zazkis (this issue), as they consider the knowledge that mathematics teachers may draw upon in responding to unexpected opportunities within mathematics lessons. Yet, the mathematical properties entailed in the two tasks are different.]

In the Fractions Task, the prospective teacher encounters a situation in which an elementary school student proposes a novel method for finding a fraction between two given (positive and non-equivalent) fractions. In part A of the Task, the prospective teachers are asked to check the student's method with different pairs of fractions, and in part B to use their work in part A in order to come up with a possible general rule for finding a fraction between any two given fractions. The rule that the prospective teachers are expected to find 
in part B can be expressed algebraically as follows (non-algebraic representations are also possible):

Given two fractions $\frac{a}{b}$ and $\frac{c}{d}$ (where $a, b, c, d>0$ and $\frac{a}{b}<\frac{c}{d}$ ), then: $\frac{a}{b}<\frac{a+c}{b+d}<\frac{c}{d}$.

Although it may seem to be counterintuitive, the above rule is true (the rule utilizes the “mediant property of positive fractions”). From a mathematical standpoint, the prospective teachers could not be sure whether and why the rule was true unless they developed a proof for it or had seen it before (which was unlikely) (for possible proofs see Stylianides and Stylianides [2010, pp. 165-166]). In part C, prospective teachers are asked to consider the appropriateness of using this rule with their fifth-grade students. Note that the development of a proof is not required in order for prospective teachers to respond to part C of the task. A major idea that part $\mathrm{C}$ aimed to assess was whether the prospective teachers would trust the rule based on examinations of particular cases in which they checked the rule or whether they would express skepticism about accepting the rule in the absence of a proof. In Table 2 we provide a small set of sample responses to parts B and C of the Fraction Task.

As researchers who are interested in analyzing prospective teachers' responses to the Fractions Task, we may be interested in determining the extent to which the questions in the task draw upon respondents' conceptual knowledge and/or procedural knowledge. More specifically, Do parts B and C of the Fraction Task assess prospective teachers' procedural and/or conceptual knowledge? We aim to show that, depending on the perspective that one takes, there are several answers that one could provide to this query. Consider the following hypothetical responses:

Answer 1. Part B assesses procedural knowledge, because this question concerns teachers' knowledge about a student's procedure. In part A, prospective teachers attempt to comprehend the student's procedure, and in part B prospective teachers state a rule that describes the student's procedure. Looking at the sample data in Table 2, note that 
prospective teacher 1 (PT1) is able to comprehend the student's procedure correctly, while both PT2 and PT3 have difficulty doing so. In any of these cases, an argument can be made that questions about procedures are likely to (and perhaps by definition) tap procedural knowledge.

Answer 2. Part B assesses procedural knowledge, because some prospective teachers may have previously learned about the mediant property of positive fractions and could merely recall the property without a great deal of thought. Looking at the sample data, perhaps PT1's correct response was possible because he/she could recall this property from memory without thinking, rather than as a result of an analysis of the student's work in part A (yet, PT1's response to part C of the task seems to refute this hypothesis). Easy and quick recall from memory may not indicate or require understanding, so in this case perhaps one might argue that part B requires only procedural knowledge.

Answer 3. Part B assesses conceptual knowledge, because it requires that prospective teachers make sense of what the student did (in part A) and then think how the student's method could be generalized into a rule that could be applied to any given pair of positive, non-equivalent fractions. Making sense of the student's work and identifying the generalizable features of its method draws upon prospective teachers' knowledge of other, related concepts and procedures within the domain of fractions and even algebra, and thus may be considered conceptual.

Answer 4. Part $\mathrm{C}$ assesses conceptual knowledge, because determining the appropriateness of an instructional decision (from a mathematical standpoint) requires that prospective teachers draw upon a significant body of other, related knowledge. For example, in the sample responses, PT1 notes the importance of an explanation for why the rule works (i.e., a proof), in order to determine the appropriateness of presenting this rule to students. 
Answer 5. It is impossible to determine whether parts B and C assesses conceptual and/or procedural knowledge, because we lack sufficiently fine-grained information for making this determination. In the sample data, the short written responses from PT1, PT2, and PT3 are far from conclusive about the state of their knowledge (e.g., is the hypothesis described in Answer 2 above about PT1's prior knowledge of the mediant property of positive fractions correct?). Perhaps we would need a more detailed response from prospective teachers, or maybe even an opportunity to interview each of them to probe their knowledge in greater depth.

Answer 6. It is impossible to determine whether parts B and C assess conceptual and/or procedural knowledge, because this determination requires that we be clearer about what we mean by procedural knowledge and conceptual knowledge. Perhaps the procedural and conceptual knowledge are so tightly connected that attempting to distinguish between them is so fundamentally flawed and nebulous that this is not a useful question to ask.

What we seek to illustrate in this exploration of the Fraction Task and selected responses from prospective teachers is that there is a wide variety of responses to our query of whether parts B and C assess conceptual and/or procedural knowledge. Depending on one's perspective, this task could assess conceptual knowledge, procedural knowledge, neither, or both. Earlier we noted that for a terminological framework such as conceptual/procedural knowledge to realize its role to encapsulate a rich and nuanced collection of ideas about the teaching and learning of mathematics, there must be general agreement among users of the framework about what conceptual and procedural knowledge are and how they might look like. Based on our analysis above, it appears that such an agreement may be hard to achieve. In the following two sections, we continue to explore the different ways that tasks such as the Fraction Task can tap students' or teachers' conceptual 
and/or procedural knowledge, by returning to the knowledge type versus knowledge quality distinction discussed above.

\section{Conceptual and Procedural Knowledge as Types of Knowledge}

Within the psychological literature, it is relatively common to find studies of mathematics learning where conceptual and procedural knowledge are defined as types. In some studies, these terms are explicitly defined; in others, one can make a reasonable inference from examples of measures used in the study.

For example, Rittle-Johnson and Alibali’s (1999) widely cited empirical study on conceptual and procedural knowledge in mathematics defined conceptual and procedural knowledge as follows:

We define conceptual knowledge as explicit or implicit understanding of the principles that govern a domain and of the interrelations between pieces of knowledge in a domain. We define procedural knowledge as action sequences for solving problems. (p. 175)

Despite the use of the word "understanding" in the definition of conceptual knowledge, the researchers did not include in their measures features to determine the quality of students' conceptual knowledge-only whether students demonstrated knowledge of a concept. An example of an item that assessed conceptual knowledge was a short answer question that asked students to define the equals sign. In another conceptual knowledge item, students were presented with various possible definitions of the equals sign and were asked to rate the definitions as "very smart, kind of smart, or not so smart.” In all items examining procedural knowledge, students were presented with equivalence problems (e.g., $3+4+5=3+\ldots$ ); correct completion of a problem was presumed to indicate procedural knowledge.

In more recent work (e.g., Rittle-Johnson, Siegler, \& Alibali, 2001; Rittle-Johnson \& Star, 2007), similar definitions and operationalizations of conceptual and procedural 
knowledge as types were present. Rittle-Johnson and colleagues' work drew upon earlier work by Byrnes and colleagues, who also viewed conceptual and procedural knowledge as types. For example, in another widely cited paper, Byrnes and Wasik (1991) noted the following:

Conceptual knowledge, which consists of the core concepts for a domain and their interrelations (i.e., "knowing that"), has been characterized using several different constructs, including semantic nets, hierarchies, and mental models. Procedural knowledge, on the other hand, is "knowing how" or the knowledge of the steps required to attain various goals. Procedures have been characterized using such constructs as skills, strategies, productions, and interiorized actions. (p. 777)

As an example of a conceptual knowledge item in Byrnes and Wasik (1991), students were shown six triangles, with five of them shaded, and asked (via a multiple choice item) to identify what fraction of the set of triangles were shaded. On all procedural knowledge items, students were given a fraction addition or multiplication item and were asked to compute the sum or product.

Within the experimental paradigm that is dominant in psychological research, it is crucial that constructs of interest (such as conceptual and procedural knowledge of students' learning of mathematics) are easily and reliably measured. Thus it is perhaps not surprising that the knowledge type interpretation is prevalent in psychological research, as knowledge type arguably is easier to measure than knowledge quality (as we discuss in a following section). Furthermore, the existence (from prior research) of measures of conceptual and procedural knowledge as types within certain mathematical domains (e.g., probability, fractions), has led some psychologists to pursue certain types of questions related to students' mathematical knowledge that they believe have implications to mathematics educators' concerns about instruction. In particular, there has been some interest in psychological 
research in determining whether conceptual knowledge or procedural knowledge should come first in instruction (e.g., Rittle-Johnson \& Alibali, 1999; Rittle-Johnson \& Siegler, 1998; Rittle-Johnson, et al., 2001) and how these two kinds of knowledge are related (Schneider, Rittle-Johnson, \& Star, 2011).

Returning to prospective teachers' responses to the Fraction Task (see Table 2), and the possible responses to our query about whether parts B and/or C assess conceptual and/or procedural knowledge, we view Answers 1, 3, and 4 to be representative of what one might see in psychological research. Answer 1 notes that part B asks a question about procedures (a type of knowledge), so this question taps procedural knowledge. Similarly, Answers 3 and 4 note that parts B and C seem to require knowledge of principles, facts, and concepts, so the type of knowledge that these questions assess is conceptual.

To summarize, viewing conceptual and procedural knowledge as types of knowledge appears to be relatively common in psychological research studying mathematics teaching and learning, aligns with the need in psychological research to have easy to administer and reliable measures, and allows for the exploration of questions that psychologists believe are important and relevant to mathematics teaching and learning.

Conceptual and Procedural Knowledge as Qualities of Knowledge

In contrast to psychological research, it is relatively common in mathematics education research to see conceptual knowledge defined and operationalized as a quality. [It is difficult to find studies that assess the quality of students' procedural knowledge. As noted in Star (2005), many mathematics education researchers appear to view procedural knowledge as, by definition, rote learning.] In general, there seems to be the view in mathematics education research that written assessments (particularly multiple choice questions) are not adequate for assessing the quality of students' conceptual knowledge, because "students can answer questions and solve problems correctly without necessarily 
understanding the material” (Porter \& Masingila, 2000, p. 167). As a result, the quality of students’ conceptual knowledge is more frequently assessed using other techniques.

For example, there is a body of mathematics education research that used concept maps to assess conceptual knowledge (e.g., Bolte, 1999; Hasemann \& Mansfield, 1995; Williams, 1998). A literal reading of Hiebert and LeFevre’s (1986) definition of conceptual knowledge indicates that the presence of links and connections is fundamental. There also seems to be the perception that, "the more connections that exist among facts, ideas, and procedures, the better the understanding” (Williams, 1998, p. 414). Thus concept maps are commonly used to provide a way to measure the quality of students' conceptual knowledge, “information about students’ conceptual understanding that would not have been obtained using other methods” (Hasemann \& Mansfield, 1995, p. 45).

In addition, interviews have been used frequently in mathematics education research to investigate the quality of students' understanding of particular concepts. For example, Roh (2008) studied students' understanding of the concept of limit by conducting several taskbased interviews. Cramer and Wyberg (2009) interviewed students to learn about their understanding of fraction concepts. Interviews were also used to investigate preservice teachers' (Wilson, 1994) and students' (Hazzan \& Goldenberg, 1997) understanding of the concept of function. Such studies seem to illustrate the belief in mathematics education research that, in order to document the development, as well as the nuance and complexity, of mathematical understanding, qualitative methodologies such as interviews are important (if not essential).

Arguably, a central question in mathematics education research concerns how instructional environments, including factors like teaching and curriculum, can be designed so as to increase the chances that students will develop mathematical understanding. Thus, with understanding as a critically important but nuanced outcome, research in this field is 
naturally inclined to consider more qualitative aspects of conceptual knowledge.

Thinking again about prospective teachers' responses to the Fraction Task and the responses to our query about parts $\mathrm{B}$ and $\mathrm{C}$, we view Answers 2, 3, 4, and 5 to be representative of what one might see in mathematics education research. In Answer 2, recall of facts from memory without significant thought is by definition rote or procedural in quality. Answers 3 and 4 both highlight the importance of the connections between students' knowledge of concepts and procedures. Answer 5 echoes the view expressed above, where qualitative methods such as interviews are necessary to capture the complexity of conceptual knowledge.

To summarize, viewing conceptual and procedural knowledge as focusing on qualities of knowledge appears to be common in mathematics education research and is closely related to questions about how we should teach to promote students' understanding, which is a fundamental issue within the field of mathematics education.

\section{Challenges in Connecting Type and Quality}

In the proceeding two sections, we argued that, while mathematics educators and psychologists interested in mathematics teaching and learning tend to use the same terminological framework of conceptual and procedural knowledge, these two communities of scholars seem to lack general agreement on what the constructs in this framework mean. Psychologists (i.e., scholars who conduct psychological research) tend to refer to conceptual and procedural knowledge as types of knowledge, while mathematics educators (i.e., scholars who conduct mathematics education research) tend to refer to these constructs as qualities of knowledge. These differing perspectives on conceptual and procedural knowledge seem to be deeply rooted in each discipline’s research traditions.

From the perspective of those who view conceptual and procedural knowledge as types of knowledge, it is quite difficult to conceive of conceptual/procedural as qualities of 
knowledge. As noted above, psychologists require constructs to be easily and reliably assessable; conceptual and procedural knowledge as qualities are difficult to assess. In fact, psychologists might complain that mathematics educators have trouble deciding whether a given assessment question taps conceptual knowledge (e.g., as exemplified in Answer 5, above). Consider the sample conceptual knowledge item from Rittle-Johnson and Alibali (1999) mentioned above, where students were given a short answer question and were asked to define the equals sign. For psychologists, this item unquestionably assesses conceptual knowledge, because it taps a type of knowledge (a concept). However, and from our experience, if mathematics educators were asked if this item assessed conceptual knowledge, they likely would answer: "It depends.” In order for mathematics educators to say whether or not this item measures conceptual knowledge, they would likely want to know whether the respondent understood the definition and had not merely memorized it. Furthermore, for mathematics educators, an assessment question may indicate the presence of conceptual knowledge in one student but fail to do so in another student, even if both students answered the question correctly. This point of view poses serious challenges to psychologists who are trying to develop assessments of conceptual and procedural knowledge that would apply for all students.

On the other hand, to mathematics educators who tend to think of conceptual and procedural knowledge as qualities, it is difficult to conceive of conceptual and procedural knowledge as types. To mathematics educators, some of the questions psychologists pose and examine (and for which viewing conceptual and procedural as types is especially useful) are not especially relevant. For example, if one conceives of conceptual and procedural knowledge as qualities, then it does not matter whether conceptual knowledge or procedural knowledge is taught first. The ultimate goal is for students to develop deep knowledge (which includes both concepts and procedures); it is not useful to ask which should come first-both 
are critically important. In fact, many mathematics educators (e.g., Gray \& Tall, 1994; Sfard, 1991) have raised questions about whether conceptual and procedural knowledge are distinct types of knowledge at all. For example, Gray and Tall (1994) suggested that successful learners of mathematics are able to integrate procedures and concepts into a knowledge structure that they refer to as a "procept."

Thus, it appears that significant obstacles stand in the way of reaching general agreement among users of the conceptual/procedural terminological framework. Not only do psychologists and mathematics educators tend to use these terms in different ways, but these differing interpretations of the conceptual and procedural knowledge framework seem to be deeply rooted in each discipline's traditions.

\section{Conclusions and Next Steps}

We believe that this situation—where psychologists and mathematics educators tend to use the same terms to refer to different kinds of mathematical knowledge but use these terms in very different ways-is problematic, in that it causes difficulties for the continued exploration of questions of interest in mathematics teaching and learning (e.g., questions about teachers' knowledge as we illustrated in the context of the Fractions Task). In addition, these different interpretations and uses of this terminological framework pose challenges to the enactment of interdisciplinary studies between mathematics educators and psychologists. Yet, arguably, this kind of interdisciplinary work is central to progress in addressing the challenge of improving the teaching and learning of mathematics. In particular, the types of studies that are especially important in today's policy climate require the collaboration of psychologists and mathematics educators (as well as mathematicians and practitioners), such as studies that explore the effectiveness of curricular interventions and professional development programs and more detailed and descriptive analyses of classroom teaching and 
student learning. What is to be done? We see two possible routes toward improving this situation.

First, we (psychologists and mathematics educators) could choose to abandon the conceptual/procedural framework entirely and select new words or phrases to describe knowledge outcomes of interest (as noted above, a variety of terminological frameworks have been used over the past century). We see this option as rather radical and perhaps introducing more problems that it might solve. In particular, coming up with new terms is difficult, and encouraging adoption of and use of the new terms will be especially challenging. Furthermore, it is not clear that new (or existing but not as widely used) terminology will be more effective at bridging the gap between knowledge type and knowledge quality, since the research methods, ideologies, and epistemologies that led to this distinction will persist within mathematics education and psychology as fields of study.

Alternatively, and acknowledging the widespread usage of these terms, we could try to raise awareness of how and why mathematics educators and psychologists use conceptual and procedural knowledge in the ways that they do. Our decision to write this paper indicates our desire to pursue this second option. Raising awareness means making clear in our work which aspect(s) of conceptual and procedural knowledge we are focusing on. Furthermore, this second option would require researchers who choose to use these terms to be more precise about their meaning, thus increasing the chances that other researchers can use, test, and build on existing findings. In fact, if we refer back to the discussion of Answers 3 and 4 in the Fractions Task, we can see that there is a potential overlap in the mathematics education and psychological ways of viewing the procedural/conceptual framework. This implies that there is some common ground between mathematics education and psychological research that can serve as a foundation for future efforts to increase the precision with which these terms are being used. 
In addition, and still in relation to the second option, we think it is important to begin to develop detailed conceptualizations for conceptual and procedural knowledge that represent a more complete vision for what these terms mean. For such conceptualizations to be most useful they would need to be operational and applicable across mathematical domains (algebra, geometry, arithmetic, etc.) and across levels of education (including university mathematics) so that there is continuity and coherence.

We understand that what we propose here is challenging. Yet, the need for developing such conceptualizations is quite clear and, in the very least, we believe it is worth a serious try. Within mathematics education, similarly difficult issues have been raised with other important notions such as the notion of "proof", and significant progress has been made in addressing them (e.g., Stylianides, 2007). Making progress in developing the conceptualizations we discussed earlier can have important implications for both research and practice, including the mathematical preparation of teachers. For example, deepening our understanding of what "superficial conceptual knowledge” and “deep procedural knowledge” might mean and look like in the work of mathematics teaching would allow teacher educators to design opportunities for prospective teachers to develop these kinds of knowledge. 


\section{References}

Bolte, L. A. (1999). Using Concept Maps and Interpretive Essays for Assessment in Mathematics. School Science and Mathematics, 99(1), 19-30.

Brownell, W. A. (1944/1945). When is arithmetic meaningful? Journal of Educational Research, 38(7), 481-498.

Byrnes, J. P., \& Wasik, B. A. (1991). Role of conceptual knowledge in mathematical procedural learning. Developmental Psychology, 5, 777-786.

Cramer, K., \& Wyberg, T. (2009). Efficacy of different concrete models for teaching the part-whole construct for fractions. Mathematical Thinking and Learning, 11(4), 226257.

De Jong, T., \& Ferguson-Hessler, M. (1996). Types and qualities of knowledge. Educational Psychologist, 31(2), 105-113.

Glaser, R. (1991). The maturing of the relationship between the science of learning and cognition and educational practice. Learning and Instruction, 1, 129-144.

Gray, E. M., \& Tall, D. O. (1994). Duality, ambiguity, and flexibility: A proceptual view of simple arithmetic. Journal for Research in Mathematics Education, 26(2), 115-141.

Hasemann, K., \& Mansfield, H. (1995). Concept mapping in research on mathematical knowledge development: Background, methods, findings and conclusions. Educational Studies in Mathematics, 29(1), 45-72.

Hatano, G., \& Inagaki, K. (1986). Two courses of expertise. In H. Stevenson, H. Azuma, \& K. Hakuta (Eds.), Child development and education in Japan (pp. 262-272). New York: W.H. Freeman and Company.

Hazzan, O., \& Goldenberg, P. (1997). Students' understanding of the notion of function in dynamic geometry environments. International Journal of Computers for Mathematical Learning, 1, 263-291. 
Hiebert, J. (Ed.). (1986). Conceptual and procedural knowledge: The case of mathematics. Hillsdale, NJ: Lawrence Erlbaum.

Hiebert, J., \& Lefevre, P. (1986). Conceptual and procedural knowledge in mathematics: An introductory analysis. In J. Hiebert (Ed.), Conceptual and procedural knowledge: The case of mathematics (pp. 1-27). Hillsdale, NJ: Lawrence Erlbaum Associates.

Porter, M. K., \& Masingila, J. O. (2000). Examining the effects of writing on conceptual and procedural knowledge in Calculus. Educational Studies in Mathematics, 42, 165-177.

Rittle-Johnson, B., \& Alibali, M. W. (1999). Conceptual and procedural knowledge: Does one lead to the other? Journal of Educational Psychology, 91(1), 1-16.

Rittle-Johnson, B., \& Siegler, R. S. (1998). The relation between conceptual and procedural knowledge in learning mathematics: A review. In C. Donlan (Ed.), The development of mathematical skills (pp. 75-110). East Sussex, UK: Psychology Press.

Rittle-Johnson, B., Siegler, R. S., \& Alibali, M. W. (2001). Developing conceptual understanding and procedural skill in mathematics: An iterative process. Journal of Educational Psychology, 93(2), 346-362.

Rittle-Johnson, B., \& Star, J. R. (2007). Does comparing solution methods facilitate conceptual and procedural knowledge? An experimental study on learning to solve equations. Journal of Educational Psychology, 99(3), 561-574.

Roh, K. H. (2008). Students' images and their understanding of definitions of the limit of a sequence. Educational Studies in Mathematics, 69(3), 217-233.

Schneider, M., Rittle-Johnson, B., \& Star, J. R. (2011). Relations between conceptual knowledge, procedural knowledge, and procedural flexibility in two samples differing in prior knowledge. Developmental Psychology, 47(6), 1525-1538. 
Sfard, A. (1991). On the dual nature of mathematical conceptions: Reflections on processes and objects as different sides of the same coin. Educational Studies in Mathematics, 22(1), 1-36.

Skemp, R. R. (1976). Relational understanding and instrumental understanding. Mathematics Teaching, 77, 20-26.

Star, J. R. (2005). Reconceptualizing procedural knowledge. Journal for Research in Mathematics Education, 36(5), 404-411.

Star, J. R. (2007). Foregrounding procedural knowledge. Journal for Research in Mathematics Education, 38(2), 132-135.

Stylianides, A. J. (2007). Proof and proving in school mathematics. Journal for Research in Mathematics Education, 38, 289-321.

Stylianides, G. J., \& Stylianides, A. J. (2009). Facilitating the transition from empirical arguments to proof. Journal for Research in Mathematics Education, 40, 314-352.

Stylianides, G. J., \& Stylianides, A. J. (2010). Mathematics for teaching: A form of applied mathematics. Teaching and Teacher Education, 26, 161-172.

Williams, C. G. (1998). Using concept maps to assess conceptual knowledge of function. Journal for Research in Mathematics Education, 29(4), 414-421.

Wilson, M. R. (1994). One preservice secondary teacher's understanding of function: The impact of a course integrating mathematical content and pedagogy. Journal for Research in Mathematics Education, 25(4), 346-370. 
Table 1. Types and Qualities of Conceptual and Procedural Knowledge

\begin{tabular}{ccc}
\hline \multirow{2}{*}{ Knowledge Type } & \multicolumn{2}{c}{ Knowledge quality } \\
\cline { 2 - 3 } & Common usage of & Deep \\
\hline Procedural & procedural knowledge & Common usage of \\
Conceptual & $?$ & conceptual knowledge \\
\hline
\end{tabular}

(Reprinted from Star (2005). Need permission.) 
Table 2. Sample Responses from Prospective Teachers (PTs) to the Fractions Task.

\begin{tabular}{|c|c|c|}
\hline & Part B response & Part C response \\
\hline PT1 & $\begin{array}{l}\text { When trying to find a fraction that } \\
\text { falls two positive different fractions, } \\
\text { add together the numerators of the two } \\
\text { fractions to determine the numerator, } \\
\text { and add together the two denominators } \\
\text { to determine the denominator of the } \\
\text { new fraction. }\end{array}$ & $\begin{array}{l}\text { I believe that if an explanation to why the rule works } \\
\text { could be determined, it would be mathematically } \\
\text { appropriate to teach this method to my students. } \\
\text { Whenever multiple ways are available to solve a } \\
\text { problem it is always appropriate to present the } \\
\text { alternatives. The only mathematical reason not to } \\
\text { teach this rule would be if some exception were found } \\
\text { that would disprove the rule. }\end{array}$ \\
\hline PT2 & $\begin{array}{l}\text { Since I found the student's findings to } \\
\text { be accurate, my rule would be: In } \\
\text { order to find a fraction that is between } \\
\text { two given fractions less than 1, add the } \\
\text { two fractions together to find a } \\
\text { solution. }\end{array}$ & $\begin{array}{l}\text { Yes, because it would be simple enough to remember } \\
\text { in this situation. As soon as a student would see a } \\
\text { question like this on a homework assignment or test, } \\
\text { he/she would know to automatically add the two } \\
\text { fractions together in find an answer as long as the two } \\
\text { fractions were less than } 1 \text {. }\end{array}$ \\
\hline PT3 & $\begin{array}{l}\text { A possible rule could be adding the } \\
\text { fractions and then dividing by two. }\end{array}$ & $\begin{array}{l}\text { I am not sure if I would be able to show/teach the rule } \\
\text { I stated above because it seems like too many steps } \\
\text { for them to do. The method I did in the above } \\
\text { example is showing the midpoint of the two fractions } \\
\text { I used. I'm not sure if elementary students would be } \\
\text { able to understand this concept. }\end{array}$ \\
\hline
\end{tabular}


Figure 1.

The Fractions Task (a modified version of this task was discussed in Stylianides and Stylianides [2010]).

A student in your fifth-grade classroom has been exploring a possible rule for finding a fraction between any two given fractions (the two fractions are positive and different from each another). Here is the student's work:

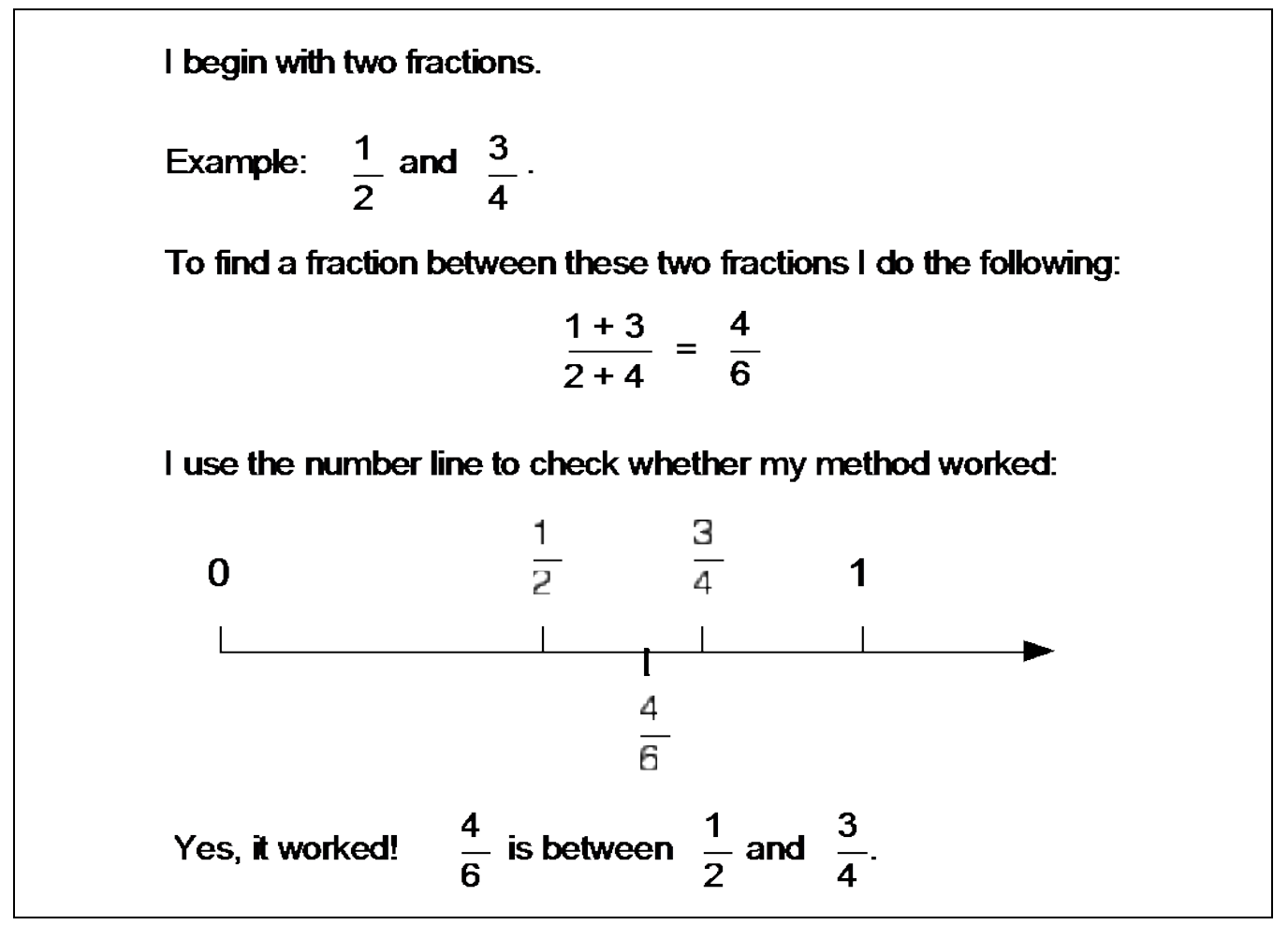

The student's exploration has attracted your attention and you have decided to pursue the exploration further.

A. Read carefully the student's method for finding a fraction between two given fractions (the two fractions are positive and different from each other) and check whether this method works with other pairs of fractions.

B. Given your earlier exploration, can you state a possible rule for finding a fraction between any two given fractions? Be precise.

C. From a mathematical point of view, would it be appropriate for you to show/teach the possible rule you stated above to your students? Why or why not?

[Note: In this question, you should focus on the mathematics. You should not be concerned about teaching issues such as whether your students should/can learn a way for finding a fraction between any two given fractions, whether you would have the time to teach this topic to them, etc.] 